\title{
Cable length optimization for trawl fuel consumption reduction
}

\author{
Ramez Khaled $^{\mathrm{a}, *}$, Daniel Priour ${ }^{\mathrm{a}}$, Jean-Yves Billard ${ }^{\mathrm{b}}$ \\ a Hydrodynamic and Metocean Service, IFREMER, BP 70, 29280 Plouzané, France \\ b IRENAV, Ecole Navale, 29240 Brest, France \\ *: Corresponding author : Ramez Khaled, tel.: +33 298224181 ; email address : $\underline{\text { Ramez.Khaled@gmail.com }}$
}

\begin{abstract}
:
A numerical method for optimization of the cable lengths in trawls with respect to the ratio between the estimated trawl drag and the predicted catch efficiency is developed and applied. The trawl cables of interest are warps, bridles, headline and footrope. The optimization algorithm applies an ordered sequential process changing one cable length at the time. It is assumed in the predictions that the catch efficiency of the trawl is proportional with the trawl mouth area. In a case study optimizing a bottom trawl used on a research vessel by applying the new method it is predicted that it would be possible to reduce the ratio between trawl drag and catch efficiency by up to $46 \%$ by optimizing the cable lengths. Thus this would enable a considerable reduction in fuel consumption to catch a specific amount of fish. Moreover, we predict an increase in the value of the trawl mouth area leading to better catching efficiency without increase in otter door drag.
\end{abstract}

\section{Highlights}

We apply energy efficiency optimization to the redesign of trawl cables. The redesign includes warps, bridles, selvedges, headline and footrope. Energy is minimized with account for fish spatial distribution. - Our work leads to an important fuel saving that might reach $46 \%$. Catching efficiency enhanced without simultaneous otter door drag increase.

Keywords: Bottom trawl ; Modeling ; Optimization ; Fuel consumption ; Drag ; Swept area ; Mouth surface ; Fish distribution 
2 In the fishing industry, fuel consumption is an issue of paramount importance to 3 fishermen and affects a number of environmental effects (such as Carbon dioxide 4 emission [Lee]) in the present context of sustainable development.

5 Budgeting energy consumption is an important issue in the trawl fishing industry 6 since total cost might reach several ten percent of the turnover.

7 Fossil energy (fuel) consumed per fish captured is typically considered as a measure 8 to such dependence on energy. Fuel consumption normal mean value is around 90.6 liter $/ \mathrm{kg}$ [Tye], but could vary anywhere between 0.1 to 3 liter $/ \mathrm{kg}$ depending on species of interest and corresponding fishing techniques.

11 From the Norwegian point of view, Schau et al. [Sch] suggest possible ways for reducing energy use and greenhouse gas emissions based on changing operational strategies, hull forms or the introduction of alternative energy sources.

An experimental study described by Sala et al. [Sal] evaluates the energy performance of fishing vessels under different operating conditions. It shows that fuel savings might reach a level of $15 \%$ through reducing navigation speed by half-aknot.

In another approach, Macdonald et al. [Mac] considered an alternative to trawling: jig fishing. Thomsen [Tho] has shown that ships converted from single to pair trawling saved $40-45 \%$ of fuel. Nonetheless, Rihan [Rih] suggested to get back to traditional single rig trawling from twin rigs in order to decrease fuel consumption.

Trawl is one of the main fishing tools used in Europe and a large number of studies have been dedicated to its use in the fishing industry. 
The improvement of fuel consumption can be achieved by geometrical or physical modification of trawls to make them fuel efficient. Using the concept of hydrodynamic resistance Kim et al. [Kima] developed a new analysis of fishing gear performance using computer simulation. As an example of gear modifications, he analysed decrease of twine diameter or increase of mesh size in order to assess the impact of these alterations on fuel consumption. In the same way Ward et al. [War] have tested reduction of twine diameter and increase of mesh sizes.

Trawl energy consumption depends on the drag it exerts and in previous works such as the following references [Pria,Khaa,Khab], we focused on panel cutting and design for fuel consumption reduction. While this might be satisfactory from the designer point of view, fishermen might differ and tend to avoid reworking panel design as it is generally considered as a rather tedious task.

Drawing from our previous work that dealt with an automatic optimization procedure of trawl panel cuttings as parameters, we changed the focus of our procedure using cable lengths as parameters.

The goal is to minimize the ratio of trawl drag to trawl mouth area. The basic assumption of the optimization is that the catch efficiency of the trawl is proportional with the mouth area of the trawl. Under this assumption can the ratio of trawl drag to the mouth area of the trawl be used as a proxy to optimize the ratio between drag and the amount of fish caught.

In principle, the target species must be considered and in particularly their behaviour face the gear such as the escapement over the headline or the herding effect by the bridles. Our work accounts simply for fish behaviour by considering a vertical fish distribution relative to sea floor. 
We build an objective function (OF) representing the minimization problem of consumed fuel volume per captured fish mass $(\mathrm{kg})$. It is evaluated from a mechanical finite element method (FEM) model adapted to trawls. Our constrained optimization starts from a reference trawl and selects the best result among several others modified by the OF minimization process.

Our previous works were motivated by the reduction of drag that leads to decrease of fuel consumption. Because drag is mostly due to netting (see Appendix A for a general description), we focused optimization on netting design. If OF were drag, a large decrease of the netting surface might occur leading to a reduction of the catch efficiency. Consequently we define rather the OF as the ratio between drag and trawl mouth area. In addition, we have shown previously that optimization leads mostly to an increase of mouth surface rather than drag decrease. This is why we focus presently on cable lengths that are expected to have a large effect on mouth surface and a small one on drag.

We show that this tool when applied to trawl cable length design could offer potential saving in fuel consumption per $\mathrm{kg}$ of fish caught. This finding is based on the assumptions that the fuel consumption is related to the drag of the gear and that the mass of fish encountering the gear is proportional with the mouth area of the trawl.

As we found previously with SOT (Successive Optimization Tool), panel cutting optimization [Khaa] could lead to a moderate increase in catch volume that can be mitigated by decreasing the number of fishing trips.

Since this study targets redesigning cable trawl, we did not account for vessel or door modifications despite the fact substantial alterations in trawl might lead to deep changes affecting drag with subsequent alterations of door area. 
This paper is organized as follows: In section 2 we describe the physical trawl along with the numerical method covering the $\mathrm{OF}$, design variables, and constraints. Section 3 describes the optimization method, while in section 4 we present the results and section 5 carries our discussion and conclusions. Appendix A describes trawl drag evaluation. In appendix B we provide details of the trawl used in this work and in Appendix $\mathrm{C}$ we provide a simple example as an illustration of our optimization method.

\section{General description of the work}

\subsection{Bottom trawl description}

A trawl used typically in a research vessel [Stu] is displayed in fig. 1 and used in this study. The mathematical definition of the trawl and its components follow reference [Led] while the actual numerical values of the various geometrical parts of the trawl are fully provided in Appendix B for self-contained-ness. The depth at which the trawl is generally used is $81 \mathrm{~m}$ with warps of $201 \mathrm{~m}$ and bridles of $36.6 \mathrm{~m}$. Usually, the towing speed is $1.51 \mathrm{~m} / \mathrm{sec}$.

\subsection{Numerical model}

The mechanical finite element method adapted to fishing net upon which the OF is built has been described in detail previously [Prib]. The FEM model consists of triangular meshes as displayed in fig. 2 with discretization size of $2 \mathrm{~m}$ (used in optimization) and verification size of $0.5 \mathrm{~m}$. The meshing consists typically of 391 triangular elements and 73 nodes per cable (for a $2 \mathrm{~m}$ discretization step) and 
5029 triangular elements and 180 nodes per cable (for a $0.5 \mathrm{~m}$ discretization step). The FEM discretization of net and panel along with numbering scheme and assembly with supporting cables are fully detailed in fig. 3, fig. 4 and fig. 5. Starting from the full net displayed in fig. 3 we concentrate on panels 1 and 3 and show the sequential FEM processing for illustration. At the end of optimization, results are validated with another discretization size of $0.5 \mathrm{~m}$. Three percentage ratios (PR) are used in this study: $4 \%, 2 \%$ and $1 \%$. This parameter is employed for the alteration of cable length (in the pseudo code described later, $\Delta_{l}=$ cable .length $\times \mathrm{PR}$ ). The optimization process leads to three different trawls that the end user (e.g. a fishing industry representative) has to choose from on the basis of his own criteria. Optimization process is controlled by three parameters: the discretization size, the PR and the Newton-Raphson convergence threshold parameter. The first one pertains to the numerical geometry of the basic element used in the FEM model. PR affects the cable length discretization after each iteration. The influence of both parameters has already been analyzed in ref. [Pria]. In this work we refine the optimization result on the basis of tuning the Newton-Raphson parameter (NRP) such that when discretization size is $2 \mathrm{~m} \mathrm{NRP}=0.1 \mathrm{~N}$ while $\mathrm{NRP}=0.01 \mathrm{~N}$ when discretization size is $0.5 \mathrm{~m}$.

\subsection{Objective function and design variables}

In order to define the OF we recall that energy required annually during hauls is due to drag $(D)$ and the annual distance covered by hauls $(L)$. If propulsion system efficiency $(\eta)$ is known, as well as fuel work capacity $\left(h_{f}\right)$, fuel volume of the trawling operation $\left(V_{f}\right)$ can be assessed by the following relation:

$$
V_{f}=\frac{D L}{\eta h_{f}}
$$


${ }_{134} \quad \frac{V_{f}}{F}=\frac{D}{S_{i}} \frac{1}{\eta h_{f} T_{c}}$ fish distribution $\left(\mathrm{m}^{2}\right)$,

$F$ : Fish caught per year $(\mathrm{kg})$,

$S_{i}$ : Intersection between bottom trawl mouth area and fish distribution, weighted by

$L$ : Towed distance per year (m),

$T_{c}$ : Trawl catching efficiency $\left(\mathrm{kg} / \mathrm{m}^{3}\right)$.

The ratio between consumed fuel and captured fish is obtained as: 
Since it is expected that $\eta, h_{f}$ and $T_{c}$ parameters are constant, in other words, not affected by the optimization process, the OF is simply the ratio $D / S_{i}$.

\subsection{The mouth surface}

In the numerical model the netting modelled by triangular finite elements [Prib], the mouth surface being calculated as the sum of the projection of each element over the plane normal to the towing displacement. In fig. 2 we show the general aspect of the triangular elements used in the FEM.

\subsection{Constraints}

The optimization is run with a number of constraints given below:

\subsubsection{Headline covering the foot-rope}

For each combination of variables, some care should be exercised. Once the bottom trawl shape has been calculated, the foot-rope should be at least $3.5 \mathrm{~m}$ behind headline in order to avoid fish escapement above headline (fig. 6).

This covering distance $(d)$ is the horizontal length between the foot-rope and headline. In the optimization process, this geometrical constraint is always checked by monitoring the minimum covering distance and whenever it is smaller than $3.5 \mathrm{~m}$, the corresponding combination is rejected. Note that the $3.5 \mathrm{~m}$ value has been extracted from the reference trawl simulation. 


\subsubsection{Contact with sea bottom}

For some combination of variables the foot-rope could lose contact with sea bottom and consequently the trawl catching efficiency might be reduced. In each case the contact is checked and when lost the corresponding combination of variables is rejected. The contact is considered lost when the distance between the bottom of the foot-rope and the sea bottom is larger than the radius of the foot-rope. We might note, in this respect, that none gradient methods such as Powell's [Rec] enable handling OF constraints directly without having to rely on simple inspection.

\subsubsection{Panel sidelength}

During optimization one should respect a set of geometrical constraints originating from cable attachment to net panel side. For instance cable length ought to be smaller than the corresponding panel side-length depending on the side being considered (the connections between panel and cable are given mathematically by a connectivity matrix similarly to the connectivity matrix pertaining to panel inner nodes). We performed previously an optimization based on panel mesh geometry that resulted in a set of bounding lengths limiting the node excursion amplitude in each panel during every run.

\section{Optimization method}

The optimization is based on three main points :

The starting point is the OF definition. It is expected to decrease during the optimization process. In the present study, the OF is a scalar equal to ratio of trawl drag to mouth area intersecting the fish distribution. Basing on previous assumptions, 
we conclude that $\mathrm{OF}$ is proportional to the ratio of fuel quantity and amount of captured fish.

The second issue is the set of variables, which are the cable lengths. We build a vector containing all cable length variables. The size of this vector $(n b)$ is the number of cables the user chooses to modify.

The third one is the list of constraints which consist of tests that might lead to reject change in cable length. An example of constraint is that the headline must always be in front of the foot-rope ${ }^{2}$ to avoid fish escapement (see fig. 6), in other words, cables \# 4, 6, 8 and 10 (see fig. 7) must always be ahead cables \# 5, 7, 9, 11 and 12 . Another constraint is that the foot-rope (cables \# 5, 7, 9, 11 and 12 on fig. 7) must always be in contact with sea bottom.

In order to run the optimization, we have to initialize all cable lengths according to a reference trawl (fig. 1) given that they are numbered from 1 to $n b$.

The optimization method could be best described by the pseudo-code listed in the box below.

In other words, performing such optimization requires that we start from some reference values and do the following:

i) impose small modifications to the variables separately,

ii) calculate the OF after each modification,

iii) select variables leading to the best OF while respecting imposed constraints.

The above three steps are done again starting from new values of the variables until no improvement is observed in the OF.

$\overline{2}$ this constraint is realistic for most bottom trawls but not for topless design 


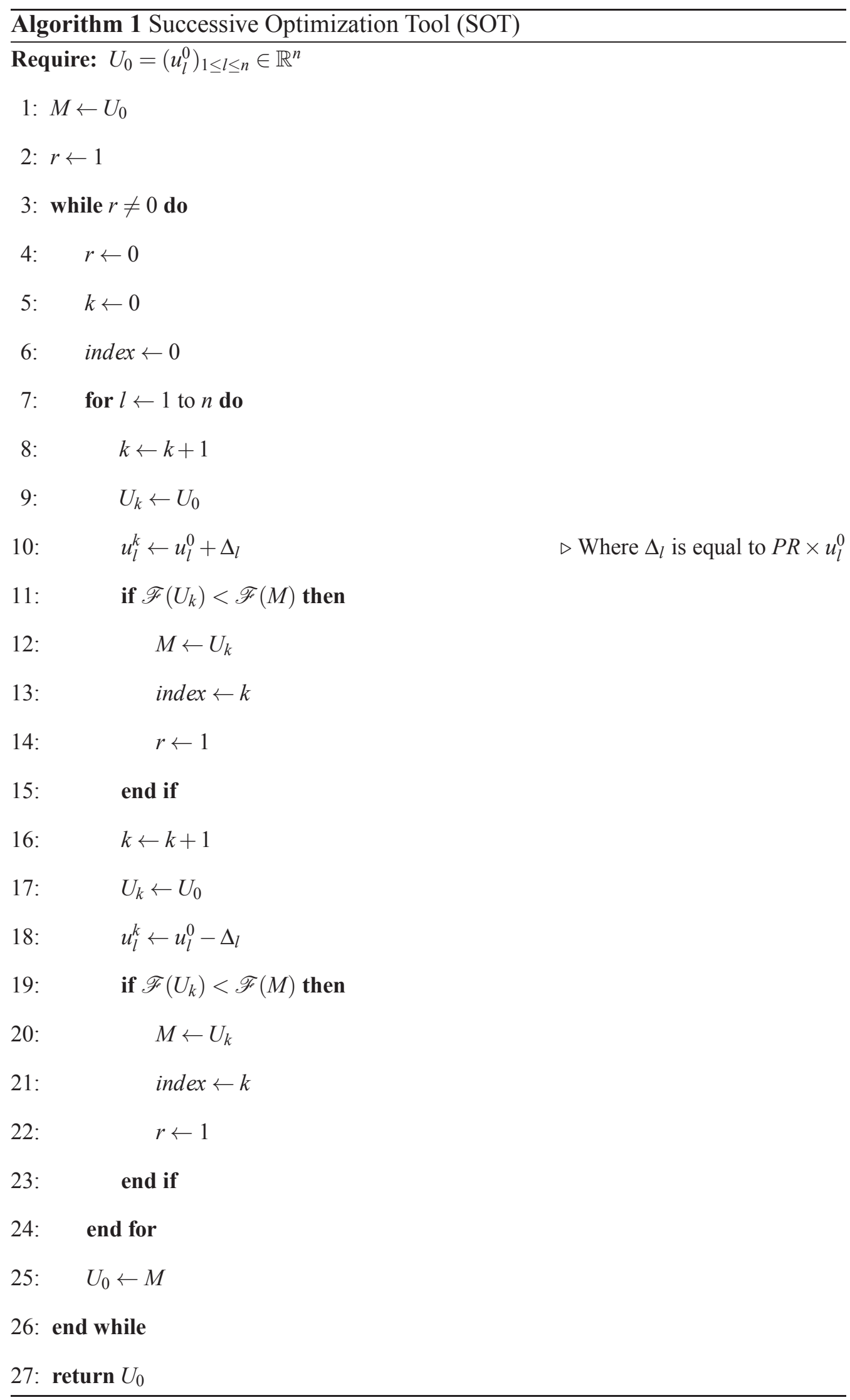


This algorithm might be improved in principle by using methods such as Powell's [Rec], however the main persisting difficulty in this type of problem, is to get stuck permanently into a local minimum.

In addition, even if we reach some global minimum, it should be close enough to the reference point since we believe that an optimized trawl should not be too much distorted geometrically with respect to the reference. This means desired characteristics of the reference trawl (in terms of catchability, selectivity etc...) ought to be approximately preserved.

Previously we used an OF given by the drag over the trawl swept width and an optimization procedure we called SOT (Successive Optimization Tool) amply described in refs. [Pria,Pric]. We found in the bottom trawl case (ref. [Khaa]), that the vertical opening of the optimized trawl was sometimes too small resulting in a potential decrease of the amount of fish caught.

This prompted us to amend the SOT optimization method through the consideration of an alternative OF given by the ratio of the drag to the effective swept area.

It will be shown later that in trawl optimization the number of variables is quite large requiring a computationally intensive effort.

The efficiency of the method depends strongly on the amount of modification of the variables. This modification is a percentage of the various trawl cable length.

Next we provide a detailed example illustrating in detail the optimization process. 


\subsection{Optimization procedure}

In the following, we provide details of a single SOT cycle. Starting from the structure displayed on fig. 1, we introduce the following vector whose components are the lengths of the variable length cables:

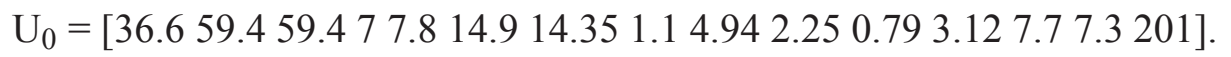

Vector component $n$ corresponds to the length of cable \# $n$ (accounting for variable length cables only). For example, the first value (36.6) is the length of cable \# 1 (bridle) in fig. 1.

This vector is modified step by step until the best solution minimizing the OF is found. The optimization is run according to the pseudo-code given above. The results of a single run are illustrated in detail below.

The 30 successive variable vectors are (numerical values are in $\mathrm{m}$ and the modified variable is in bold):

$\mathrm{U}_{1}=\left[\begin{array}{l}36.97 \\ 59.4\end{array} 59.477 .814 .914 .351 .14 .942 .250 .793 .127 .77 .3201\right]$.

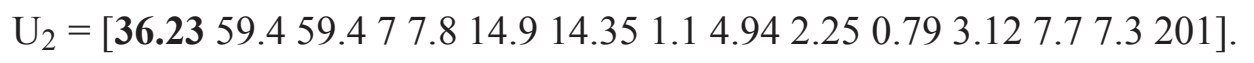

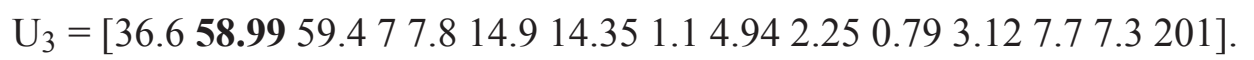

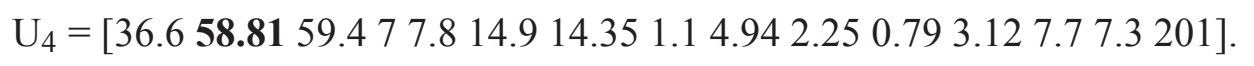

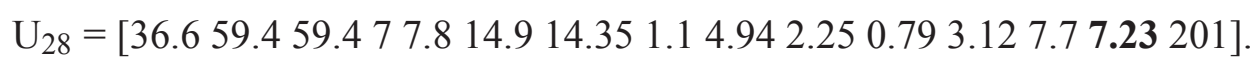

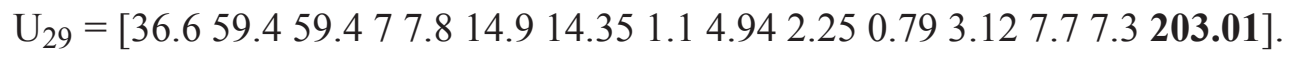

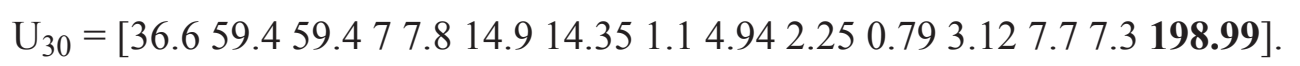

In table 1 we display results of the first and last seven cycles of the optimization 
procedure. The above vectors correspond simply to the first line of table 1 implying that modifications of cable \# 2 are mainly responsible for the OF minimization.

For each vector the shape of the trawl is calculated as well as the OF. That means 31 OF evaluations: $\mathscr{F}\left(\mathrm{U}_{0}\right)$ for the reference $\left(\mathrm{U}_{0}\right)$ while the remaining 30 OF evaluations correspond to the modifications $\left(\mathrm{U}_{1}\right.$ to $\left.\mathrm{U}_{30}\right)$. From these 30 evaluations, the minimum is extracted and corresponds to $\mathrm{U}_{n}$. If $\mathscr{F}\left(\mathrm{U}_{n}\right) \leq \mathscr{F}\left(\mathrm{U}_{0}\right), \mathrm{U}_{n}$ is the kept design and used as the new reference $\mathrm{U}_{0}$ with $\mathscr{F}$ as the OF. The process restarts from this reference: 30 modifications are applied and the OF is calculated until $\mathscr{F}\left(\mathrm{U}_{n}\right) \geq \mathscr{F}\left(\mathrm{U}_{0}\right), \quad \forall n \in[1,30]$.

The final optimized design corresponds to the last $\mathrm{U}_{0}$.

\subsection{Rounded trawl concept}

The use of the optimization tool leads to alterations of cable length. Our software is able to trace the OF minimization part for which some cable is responsible. When a given cable participation is small, its length modification is not accounted for. In summary, the optimization tool suggests some cable alteration, nevertheless the user is free to select among the most significant changes in terms of contribution to OF minimization. The resulting structure is called the rounded trawl.

\subsection{Potential time and money savings}

The potential time and money savings generated by this optimization are evaluated on the following assumptions for both bottom trawls previously described: the reference and the optimized one. 
(i) The first hypothesis is that the quantity of fish caught per year with the optimized trawl is expected to be same as the reference trawl meaning same intersection volume between the swept bottom trawl volume and fish spatial distribution. The trawl catching efficiency is expected to be constant between the reference and the optimized trawls.

(ii) The second hypothesis is that the efficiency of the engine and propeller equals $10 \%$, the energy per liter of fuel equals $36 \mathrm{MJ} / 1$ and the fuel costs $0.6 € / 1$. Note that these values are acceptable in the year 2012 .

(iii) The third hypothesis is that the duration of trawling of the reference trawl is $21 \mathrm{~h}$ and 36 minutes per day during 260 days. This duration is calculated from usual week trip with each haul consisting of $3 \mathrm{~h}$ of trawling and 20 minutes of hauling operations.

\section{Results}

\subsection{Rounded trawl optimization results with respect to reference trawl}

We start with the simulation of the reference trawl. We find that the obtained drag is $57 \mathrm{kN}$ and the mouth area is $70 \mathrm{~m}^{2}$, while its intersection with the fish distribution over $6 \mathrm{~m}$ depth is $70 \mathrm{~m}^{2}$ which gives a drag per intersection swept surface equal to $809 \mathrm{~N} / \mathrm{m}^{2}$. The design of the reference trawl is displayed in fig. 1 and the shape is in fig. 8.

Once OF building has been done according to the procedure described in section 3.1, the SOT optimization is run with three PR 4\%, 2\% and 1\%. A slight modification in optimized trawls is observed while changing the PR from $4 \%$ to 
$1 \%$. We choose the results issued from PR $1 \%$.

According to table 2 and figure 9 the largest gain reduction is obtained with cables \# 2, 4 and 12. This triggered us to finalize the optimization process by changing the lengths of these cables in the reference trawl only. In the next two tables we compare the results of the rounded trawl with the full optimization.

We provide below two tables (3 and 4) carrying the optimization results and the consequences in terms of energy saving. In table 3, the drag, the actual mouth surface, the intersection area with fish distribution $\left(S_{i}\right)$, the OF $\left(\mathrm{drag} / S_{i}\right)$, the vertical opening ( $V O$ : vertical opening at middle headline), the horizontal opening ( $H O$ : mean wing ends spread) and the $D O$ (door opening or distance between doors) are given. In contrast, table 4 displays the optimized results versus reference design values with their corresponding impact on fuel consumption, fishing trip duration and energy saving. Additionally we note an increase in the value of $D O$ in the optimized case signifying an improvement of trawl catching efficiency without simultaneous enhancement of otter door drag.

We obtain a net fuel consumption reduction of $46 \%$ and the corresponding $3 \mathrm{D}$ shape is shown below in fig. 10 .

A slight increase in optimized trawl width is observed (from $24.3 \mathrm{~m}$ to $24.6 \mathrm{~m}$ ) as well as in height (from $3.5 \mathrm{~m}$ to $6.1 \mathrm{~m}$ ) leading to an increase of effective mouth surface and therefore a decrease in the number of fishing trips.

From the above results, a numerical issue should be addressed and that is the conditioning of the optimization problem. This stems from the fact a small change (such as $1 \%$ ) in cable \# 2 produces a gain larger than $80 \%$ of the total fuel reduction gain (see fig. 11). This stems from the fact, this cable controls the headline height as 
seen in fig. 8 and labeled in fig. 1.

\subsection{Convergence speed}

The typical execution time for the optimization procedure is $3 \mathrm{~h} 51 \mathrm{mn}$ while a total number of evaluated trawls reached 2970. This shows that the computation time for each trawl is about $5 \mathrm{~s}$. The machine used is based on an 8 core (Intel Xeon ${ }^{\mathrm{TM}}$ E5345@2.33GHz) architecture with GNU gcc-4 compiler running under Linux Ubuntu 8.04. The typical variation of the OF versus iteration is displayed in fig. 12 .

\subsection{Resulting savings in time and money}

Reduction of fuel consumption as well as economy and savings in terms of distance covered, trips and energy expanded are displayed in table 4. Reference trawl is displayed in fig. 8 and the rounded trawl is in fig. 10. Notice that the latter corresponds to the rounded case and not the optimized one. Rounded, in this case, means results are collected with the principal cables (meaning those giving the largest reduction i.e. cables \# 2, 4 and 12) and not all cables.

Considering our general assumptions defined in section 3.3, we infer that total trip duration per year with the optimized trawl is decreased by 116 days $(-45 \%)$. Hence the expected economy of fuel cost might reach about $123 \mathrm{k} €$ per year equivalent to a net savings of $46 \%$. 


\section{Conclusion and discussion}

Optimization based on cable length modification is found to be beneficial for bottom trawl fuel consumption. In this work, we proceed by changing trawl cable lengths while maintaining netting panel geometry in contrast to our previous work. In the past, optimization focused solely on panel cutting, but fishermen prefer cable length modification over netting panel redesign since it does not entail a number of delicate and time consuming operations.

The application of this tool to design a bottom trawl used in research vessel [Stu] leads in the $6 \mathrm{~m}$ depth uniform fish distribution to an important fuel saving, the largest reduction being obtained with cables \# 2, 4 and 12.

When we finalize the optimization process by rounding the lengths of the latter cables, we reach a substantial improvement in terms of energy efficiency savings for bottom trawl (about 46\%).

OF depends on spatial fish distribution since it is given by the ratio of drag to effective swept area $S_{i}$. The latter is determined by the intersection of trawl mouth surface with the area over which fish population is distributed. Uniform distribution over 6 meters depth is assumed in this work. From our results, it appears that improvement is mostly due to increase of effective surface $(80 \%)$ rather than drag decrease $(2 \%)$.

During optimization, the modification size (PR) cannot be a priori determined. This is why the optimization has been carried out using several values as percentages. The user has finally to choose among the different results. These range from $4 \%$ to $1 \%$ since a number of geometrical constraints impose several bounds on these 
modifications. An example of geometrical constraint is that a cable attached to a panel cannot be substantially modified, since its length should be smaller than the panel side-length to which it is attached.

Despite the quality of the results we obtain with the chosen set of modifications, the issue of being stuck in a local minimum without being able to escape from it due to the various geometrical constraints remains. Nevertheless, performing geometrically constrained optimization can be done by incorporating a procedure to escape from the local minimum. Such procedure might be based, for instance, on stochastic methods such as simulated annealing [Rec].

Another issue related to this work is fish behaviour during trawling. Several factors affect fish behaviour such as fish size, species and water temperature. In the case of flat-fish, Ryer [Rye] shows that its capture can be viewed as a sequence of behavioral patterns with respect to the gear. When the fish is in the path of the sweep, its behavioural response determines whether the flat-fish is herded, or passes over or under the sweep. In contrast to round-fish, flat-fish reaction distance is quite small (typically less than $1 \mathrm{~m}$ ). When herding is initiated, a second behavioural response determines whether herding is maintained. In this case fish could reach the footrope. Generally, the angle of the foot-rope is close to $90^{\circ}$ in contrast to the bridles where the angle is smaller and because the diameter of the foot-rope is usually larger than that of the bridle. Fish enters the net after cessation of herding and fatigue. All these behaviours occur close to sea bottom. In sharp contrast, round-fish demonstrates generally greater endurance in the same circumstances.

In the case of Nephrops, Main and Sangster [Mai] showed that a combination of behaviour and trawl design must be considered. They determined that the Nephrops during trawling do not swim higher than $1 \mathrm{~m}$ from seabed and enter the net only 
trough the width of the bosom ground-line. When the Nephrops are in the sweep path, most of them are overrun by the sweeps and the bridles. Bridles do not have any effect on herding neither on catch. Same applies to sweeps.

While few works on numerical models of fish behaviour in presence of fishing nets exist, Kim and Wardle [Kimb] derived one in the case where fish is in front of the gears and Herrmann [Her] focused on its behaviour in cod-ends.

Our work is mainly focused on the optimization process and the modeling of the catching process does not account for the detailed fish behaviour as discussed above.

On the other hand, since our work is mainly numerical, we intend, in the future, to validate it experimentally by a model scale work in a flume tank through measuring the ratio of trawl drag to mouth area for both the reference trawl and the optimized one with this method.

In this work, we have performed optimization based on cable lengths that are geometrically constrained by being smaller than panel side-length. We have extended our previous optimization method dealing with panel mesh geometry where the constraint is such that panel side-length must be larger than cable length and a set of bounding lengths limiting the node excursion amplitude in each panel during every optimization run.

This contradictory set of geometrical constraints will be handled in our future work consisting of full optimization of cables and panels simultaneously in order to achieve further reduction of fuel consumption.

In Table 4 we display drag reduction in the optimized trawl case. This reduction might trigger discussions with the fishermen as far as adjusting door surface area or 
propulsion efficiency are concerned. These parameters are considered constant in this work. When these parameters are included in the optimization process, and if the relationship between drag and these parameters is known, then a new simulation platform can be precisely defined for future studies. 
In table 5, the drag distribution between the trawl components are shown for some examples of bottom trawl. It can be seen that most of the drag is due to the netting.

The FEM model described in ref. [Prib] calculates the drag and the swept area of trawls taking into account the following forces exerted on the structure:

- The inner tension in twines:

$T_{n}=E A \frac{n-n_{0}}{n_{0}}$

$T_{n}$ : Tension in twines $(\mathrm{N})$,

$E$ : Modulus of twine elasticity $(\mathrm{Pa})$

$A$ : Twine section $\left(\mathrm{m}^{2}\right)$,

$n_{0}$ : Unstretched length of mesh side (m),

$n$ : Stretched length of mesh side (m),

- Drag force exerted on each twine of the net by the towing speed:

5

$$
F=\frac{1}{2} \rho C_{d} D L(V \sin \theta)^{2}
$$

$T=f \frac{1}{2} \rho C_{d} D L(V \cos \theta)^{2}$

$F$ : Normal force $(\mathrm{N})$ to the twine. This expression comes from Landweber hypothesis.

$T$ : Tangential force originating from Richtmeyer hypothesis.

$\rho$ : Mass density of water (close to $1025 \mathrm{~kg} / \mathrm{m}^{3}$ ),

$C_{d}$ : Normal drag coefficient (here 1.2),

$f$ : Tangential coefficient (here 0.08),

$D$ : Diameter of the twine (m), 
$L$ : Length of the twine (m),

$V$ : Amplitude of the towing speed $(\mathrm{m} / \mathrm{sec})$,

$\theta$ : Angle between the twine and the towing speed (radian).

- The drag on the bottom:

$$
F_{c}=\mu F_{v}
$$

\section{Appendix B: Details of trawl used in the study}

The trawl drawing with all physical lengths are detailed in fig. 13.

\section{Appendix C: Simple test example for the optimization validation}

In this appendix we apply the SOT method to cable length optimization in the case of a simple rectangular panel sujected to a water flow with $0.6 \mathrm{~m} / \mathrm{sec}$ speed. The net we use is displayed in figure 14 with the following dimensions: $0.8 \mathrm{~m}$ is the warp length, $2 \mathrm{~m}$ the headline length, $3 \mathrm{~m}$ the bridle length and finally $2 \mathrm{~m}$ is the foot-rope length. The 2D geometrical aspect is shown in fig. 14 for the reference and optimized case whereas the full $3 \mathrm{D}$ form is displayed in fig. 15. The selected optimization method is the SOT with a PR equal to $2 \%$.

The net is of "Aleze PA material 600 MS $22 \mathrm{~mm}$ " type with $22 \mathrm{~mm}$ twine length and $1.75 \mathrm{~mm}$ twine diameter. The warps and rope are of the "PA" type with $6 \mathrm{~mm}$ 


\section{References}

[Her] Herrmann B., 2005. Effect of catch size and shape on the selectivity of diamond mesh cod-ends: I. Model development Fisheries Research, 71, 1-13.

[Khaa] Khaled R., Priour D., 2010. Numerical method for energy optimisation of bottom trawl. 1st Int. Symp. on Fishing Vessel Energy efficiency, Vigo, Spain.

[Khab] Khaled R., Priour D., Billard J-Y, 2011. Numerical optimization of trawl energy efficiency dependent of fish distribution (Submitted to Ocean Engineering).

[Kima] Kim H. Y., Lee C. W., Shin J. K., Kim H. S., Cha B. J., Lee G. H., 2007. Dynamic simulation of the behavior of purse seine gear and sea-trial verification, Fisheries Research, Volume 88, Issues 1-3, 109.

[Kimb] Kim Y.H. And Wardle C.S., 2005. Basic modelling of fish behaviour in a towed trawl based on chaos in decision-making, Fisheries Research, 73, 217229.

[Led] Le Dret H., Lewandowski R., Priour D., Chagneau F., 2004. Numerical simulation 
of a cod-end net. part 1: Equilibrium in a uniform flow, Journal of Elasticity, Vol. 76, No. 2, Pages 139-162.

[Lee] C-W Lee, J. Lee, M-Y Choe, 2010. Low-Carbon Fishing Gear Design Using Numerical Methods First International Symposium on Fishing Vessel Energy Efficiency E-Fishing, Vigo, Spain.

[Mac] Macdonald P., Laurenson C., Johnson A., Tait L., 2007. Jig Fishing Pilot Study in Shetland Coastal Waters. NAFC Marine Centre, Fisheries development note N.

[Mai] Main J. and Sangster G.I., 1985. The behaviour of the Norway lobster, Nephrops norvegicus, during trawling. Scottish Fisheries Research Report (24), 23 pages.

[Pria] Priour D., 2009. Numerical optimisation of trawls design to improve their energy efficiency, Fisheries Research, Volume 98, Issues 1-3, Pages 40-50.

[Prib] Priour D., 1999. Calculation of net shapes by the finite element method with triangular elements. Communications in Numerical Methods in Engineering, 15(10), 755-763.

[Pric] Priour D., Khaled R., 2009. Comparison between two methods of trawl optimisation, 13th Congress of Intl. Maritime Assoc. of Mediterranean, IMAM 2009, Istanbul, Turkey.

[Rec] Press W. H., Vetterling W. T., Teukolsky S. A. and Flannery B. P., 1992. Numerical Recipes in C: The Art of Scientific Computing Second Edition, Cambridge University Press, New-York.

[Rih] Rihan D., 2005. A comparison of twin-rig single-rig trawling in terms of relative fishing efficiency, in economic performance fishing efficiency of marine capture fisheries, FAO Fisheries Technical Paper 482, ISSN 0429-9345.

[Rye] Ryer C.H., 2008. A review of flatfish behaviour relative to trawls, Fisheries Research, 90, 138-146. 
[Sal] Sala A., De Carlo F., Buglioni G., Lucchetti A., 2011. Energy performance evaluation of fishing vessels by fuel mass flow measuring system, Ocean Engineering, Article in Press.

[Sch] Schau E. M., Ellingsen H., Endal A., Aanondsen S. A., 2009. Energy consumption in the Norwegian fisheries, Journal of Cleaner Production, Volume 17, Issue 3, Pages 325-334.

[Stu] Study of factors affecting the variability of cod-end selectivity 1998. Final Report of EC Contract No AIR2-CT94-1544, FRS Marine Laboratory, Aberdeen, Scotland.

[Tho] Thomsen B., 2005. Efficiency changes in the Faeroese pair-trawler fleet, in Economic performance fishing efficiency of marine capture fisheries, FAO fisheries technical paper 482, ISSN 0429-9345.

[Tye] Tyedmers P. H., Watson R., Pauly D., 2005. Fueling Global Fishing Fleets, Royal Swedish Academy of Sciences, Ambio Vol. 34, No. 8.

[War] Ward N., Montgomerie M., Lart W., 2005. Fuel efficiency trials using Jackson trawls with reduced twine diameter on MFV Challenge II Seafish Report No. SR578, p.31. 


\begin{tabular}{|l|c|c|c|c|}
\hline Cycle \# & $\begin{array}{c}\text { Best } \\
\text { Cable \# }\end{array}$ & $\begin{array}{c}\text { Modification } \\
(\mathbf{m})\end{array}$ & OF (N/m $\mathbf{m}^{2}$ & $\begin{array}{c}\text { Reduction per } \\
\text { Cycle (N/m }\end{array}$ \\
\hline Initial & & & 542.28 & \\
\hline $\mathbf{1}$ & 2 & +0.59 & 427.03 & 115.25 \\
\hline $\mathbf{2}$ & 4 & +0.07 & 425.15 & 1.88 \\
\hline $\mathbf{3}$ & 4 & +0.07 & 422.18 & 2.97 \\
\hline $\mathbf{4}$ & 4 & +0.07 & 421.4 & 0.78 \\
\hline $\mathbf{5}$ & 7 & +0.14 & 420.58 & 0.82 \\
\hline $\mathbf{6}$ & 6 & +0.15 & 417.76 & 2.82 \\
\hline $\mathbf{7}$ & 12 & -0.03 & 417.08 & 0.68 \\
\hline & & & & \\
\hline $\mathbf{9 3}$ & 8 & -0.01 & 400.52 & 0.06 \\
\hline $\mathbf{9 4}$ & 15 & +2.01 & 400.39 & 0.13 \\
\hline $\mathbf{9 5}$ & 8 & -0.01 & 400.36 & 0.03 \\
\hline $\mathbf{9 6}$ & 8 & -0.01 & 400.25 & 0.11 \\
\hline $\mathbf{9 7}$ & 8 & -0.01 & 400.08 & 0.17 \\
\hline $\mathbf{9 8}$ & 15 & +2.01 & 399.77 & 0.31 \\
\hline $\mathbf{9 9}$ & 11 & -0.01 & 399.76 & 0.01 \\
\hline
\end{tabular}

Table 1

Illustration of the optimization procedure according to run number and best cable with the corresponding results. The optimization is initialized with a reference variable leading to an OF value of $542.28 \mathrm{~N} / \mathrm{m}^{2}$ (first line). This shows that most of the gain is obtained during the first cycles. 


\begin{tabular}{|l|c|c|c|c|}
\hline Cable \# & RL (m) & OL (m) & LM (\%) & Gain percentage (\%) \\
\hline 1 & 36.6 & 36.6 & 0 & 0.00 \\
\hline $\mathbf{2}$ & $\mathbf{5 9 . 4}$ & $\mathbf{5 9 . 9 9}$ & $\mathbf{1}$ & $\mathbf{8 0 . 8 7}$ \\
\hline 3 & 59.4 & 59.4 & 0 & 0.00 \\
\hline $\mathbf{4}$ & $\mathbf{7}$ & $\mathbf{7 . 2 1}$ & $\mathbf{3}$ & $\mathbf{3 . 9 5}$ \\
\hline 5 & 7.8 & 7.18 & -8 & 0.43 \\
\hline 6 & 14.9 & 15.05 & 1 & 1.98 \\
\hline 7 & 14.35 & 14.49 & 1 & 0.58 \\
\hline 8 & 1.1 & 0.96 & -13 & 0.32 \\
\hline 9 & 4.94 & 4.4 & -11 & 0.61 \\
\hline 10 & 2.25 & 2.14 & -5 & 0.24 \\
\hline 11 & 0.79 & 0.73 & -7 & 0.06 \\
\hline $\mathbf{1 2}$ & $\mathbf{3 . 1 2}$ & $\mathbf{2 . 3 4}$ & $\mathbf{- 2 5}$ & $\mathbf{9 . 5 4}$ \\
\hline 13 & 7.7 & 7.16 & -7 & 0.01 \\
\hline 14 & 7.3 & 6.86 & -6 & 0.18 \\
\hline 15 & 201 & 223.11 & 11 & 1.23 \\
\hline
\end{tabular}

\section{Table 2}

For each cable, we provide the reference length (RL), optimized length (OL) and length modification (LM). The gain percentage is the amount of reduction obtained by a given cable to total gain. The rounded trawl uses only modification of cables \# 2, 4 and 12 (bold) because they lead to the most significant improvement. 


\begin{tabular}{|l|c|c|c|c|c|}
\hline \multirow{2}{*}{ Values } & \multicolumn{5}{|c|}{ SOT at 1\% } \\
\cline { 2 - 6 } & Ref & Opt & Opt vs Ref(\%) & Rnd & Rnd vs Ref(\%) \\
\hline OF $\left(\mathbf{N} / \boldsymbol{m}^{2}\right)$ & 809 & 414 & -49 & 439 & -46 \\
\hline Drag $(\boldsymbol{k})$ & 57 & 57 & 1 & 56 & -2 \\
\hline Mouth Surface $\left(\boldsymbol{m}^{2}\right)$ & 70 & 145 & 107 & 127 & 81 \\
\hline $\boldsymbol{S}_{i}\left(\boldsymbol{m}^{2}\right)$ & 70 & 138 & 97 & 126 & 80 \\
\hline VO $(\boldsymbol{m})$ & 3.5 & 6.6 & 88 & 6.1 & 72 \\
\hline HO $(\boldsymbol{m})$ & 24.3 & 25.3 & 4 & 24.6 & 1 \\
\hline DO $(\boldsymbol{m})$ & 68.5 & 73.1 & 7 & 70.4 & 3 \\
\hline Otter door forces $(\boldsymbol{N})$ & 10887 & 11086 & 1.8 & 10956 & 0.6 \\
\hline
\end{tabular}

Table 3

Optimization considering constant fish distribution over $6 \mathrm{~m}$ depth. Main optimization results are given considering modification size of $1 \%$. These results are: OF value $\left(\mathrm{Drag} / \mathrm{S}_{i}\right)$, drag of the trawl, mouth area, intersection swept mouth with fish distribution, vertical opening and horizontal opening. The figures are for the reference, optimized and rounded trawls and the differences between the optimized trawl and the rounded one are compared to the reference. Otter door forces are defined as the resulting difference between door and warp and door and bridle respectively.

\begin{tabular}{|l|c|c|}
\hline & Reference trawl & Rounded trawl \\
\hline Drag $(\mathbf{k N})$ & 57 & 56 \\
\hline HO $(\boldsymbol{m})$ & 24.3 & 24.6 \\
\hline Duration $($ days $/ \mathbf{y})$ & $\mathbf{2 6 0}$ & $\mathbf{1 4 4}$ \\
\hline Distance $(\mathrm{km} / \mathbf{y})$ & 30529 & 16931 \\
\hline $\boldsymbol{S}_{i}\left(\boldsymbol{m}^{2}\right)$ & 70 & 126 \\
\hline Volume $\left(\mathbf{k m}^{3} / \mathbf{y}\right)$ & 2.1 & 2.1 \\
\hline Drag energy $(\mathbf{M W h} / \mathbf{y})$ & 481 & 261 \\
\hline Fuel volume $\left(\mathbf{m}^{3} / \mathbf{y}\right)$ & 450 & 244 \\
\hline Fuel cost $(€ / \mathbf{y})$ & $\mathbf{2 6 9 7 8 3}$ & $\mathbf{1 4 6 4 7 5}$ \\
\hline
\end{tabular}

Table 4

Duration of the fishing trip per year, distance covered per year as well as drag, drag energy, horizontal opening, filtered volume, $S_{i}$ and fuel volume and cost for the reference trawl and the rounded one in which only the principal cables (\# 2, 4 and 12) giving the largest reduction contribution are accounted for. The main results (bold) are a reduction of fuel cost (46\%) and days at sea (45\%). 
Table 5

\begin{tabular}{|l|c|}
\hline Cables & $7 \%-8 \%$ \\
\hline Otter boards & $19 \%-21 \%$ \\
\hline Netting & $60 \%-66 \%$ \\
\hline Catch & $0 \%-10 \%$ \\
\hline Ground rope & $4 \%-5 \%$ \\
\hline Total & $100 \%$ \\
\hline
\end{tabular}

Drag distribution between bottom trawl components. These figures originate from modeling that shows that most of the drag is due to the netting.

\begin{tabular}{|l|c|c|c|}
\hline & Reference net & Optimized net & Difference (\%) \\
\hline Drag $(N)$ & 236 & 184 & -22 \\
\hline Swept surface $\left(m^{2}\right)$ & 1.08 & 1.8 & +67 \\
\hline Objective function $\left(N / m^{2}\right)$ & 218.5 & 102.2 & -53 \\
\hline
\end{tabular}

\section{Table 6}

Optimization results and comparison between reference net and optimized net for a 0.6 $\mathrm{m} / \mathrm{sec}$ speed and $270 \mathrm{~cm}$ warp separation. 
Fig. 1. Layout of reference trawl displaying cable number. Due to trawl symmetry, only half parts of back and belly are presented. The floats on the headline are displayed as well as the door (Square). The warp is cable \# 15, the bridle is \# 1, the top leg is \# 2 and the bottom leg is \# 3. Due to the large number of netting twines only 1 twine out of 10 is drawn.

Fig. 2. Triangular meshes used in the FEM model. The discretization size is $2 \mathrm{~m}$ (shown in this figure), whereas the verification size is $0.5 \mathrm{~m}$.

Fig. 3. Layout of reference trawl displaying FEM triangulation of the net with panel numbering scheme. Mesh discretization size is $2 \mathrm{~m}$. In the following fig. 4 we detail the partitioning of panel number 3 and in fig. 5 the connectivity between panels 1 and 3 and assembly with surrounding cables are displayed.

Fig. 4. Partitioning of panel number 3 into finite elements with numbering scheme. The mesh discretization size is $2 \mathrm{~m}$ on the left and $0.5 \mathrm{~m}$ on the right where nodes are displayed.

Fig. 5. Display of panels 1 and 3 showing finite element connectivity and assembly with surrounding cables.

Fig. 6. Part of the trawl (The netting has been hidden). The warps are on the left, the doors are the squares. The foot-rope is behind the headline at a distance $\mathrm{d}$.

Fig. 7. Front view shape of reference trawl displaying cable number without ancillary rigging cables nor door structure (see fig. 1). The numbering scheme is symmetric with respect to a vertical mirror plane situated at the center of the trawl. Only 1 twine out of 10 is drawn.

Fig. 8. Frontview (top) and 3D (bottom) aspects of the reference bottom trawl. We display a zoom on the netting and only 1 twine out of 10 are drawn. Since the top leg (cable \# 2 in fig. 1) supports the entire fishing net, we expect its length to play a major role as discussed in the text.

Fig. 9. Percentage length modification (lower panel) and individual percentage (upper panel) reduction attributed to each cable appearing by its contribution to total economy gain. Notice that cable \# 2 provides the largest part to total gain. 
Fig. 10. Above: Frontview of the trawl rounded through changing the lengths of cables \# 2, 4 and 12 only in the reference trawl. Below: 3D aspect of the optimized trawl.

Fig. 11. Display of trawl showing cable length modification (left) and corresponding OF reduction in percent (right).

Fig. 12. Variation of the OF as a function of iteration number in the SOT case with a PR of $1 \%$.

Fig. 13. Drawing of bottom trawl used on MFV Aalskere (extracted from ref. [Stu]).

Fig. 14. Reference net (left) with dimensions $80 \times 120$ in mesh units and optimized result (right). Cable lengths are indicated. One mesh out of two is displayed.

Fig. 15. 3D sideview of the reference net and the optimized case. 


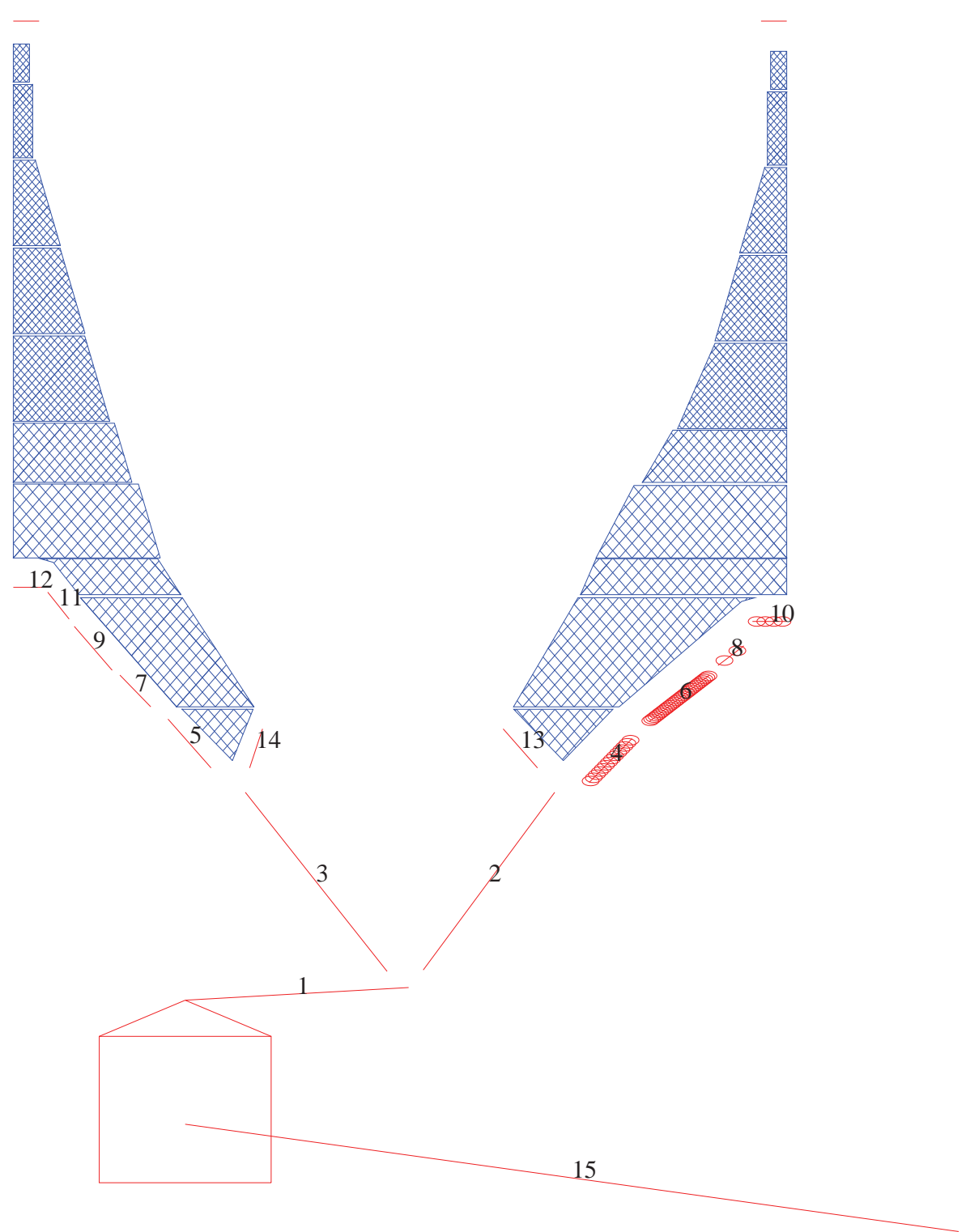

Fig. 1. Layout of reference trawl displaying cable number. Due to trawl symmetry, only half parts of back and belly are presented. The floats on the headline are displayed as well as the door (Square). The warp is cable \# 15, the bridle is \# 1, the top leg is \# 2 and the bottom leg is \# 3. Due to the large number of netting twines only 1 twine out of 10 is drawn. 


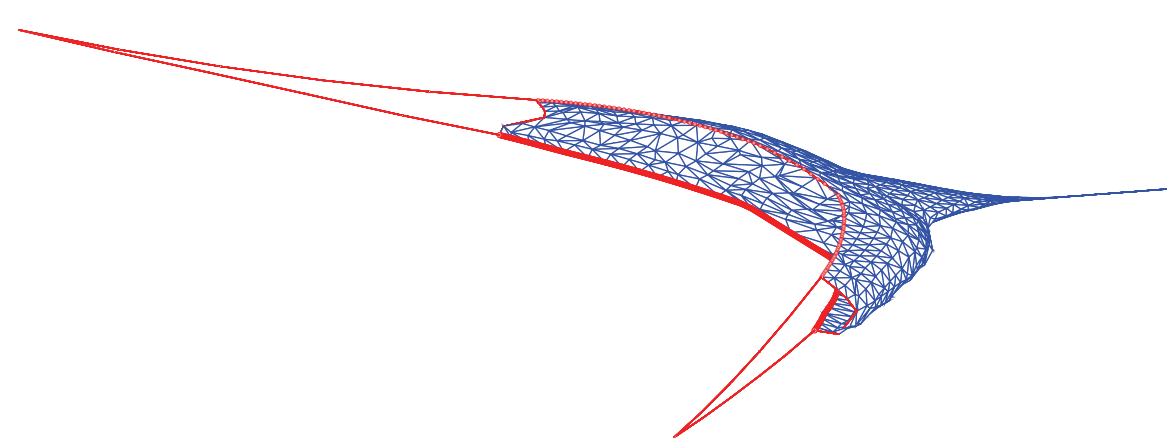

Fig. 2. Triangular meshes used in the FEM model. The discretization size is $2 \mathrm{~m}$ (shown in this figure), whereas the verification size is $0.5 \mathrm{~m}$. 


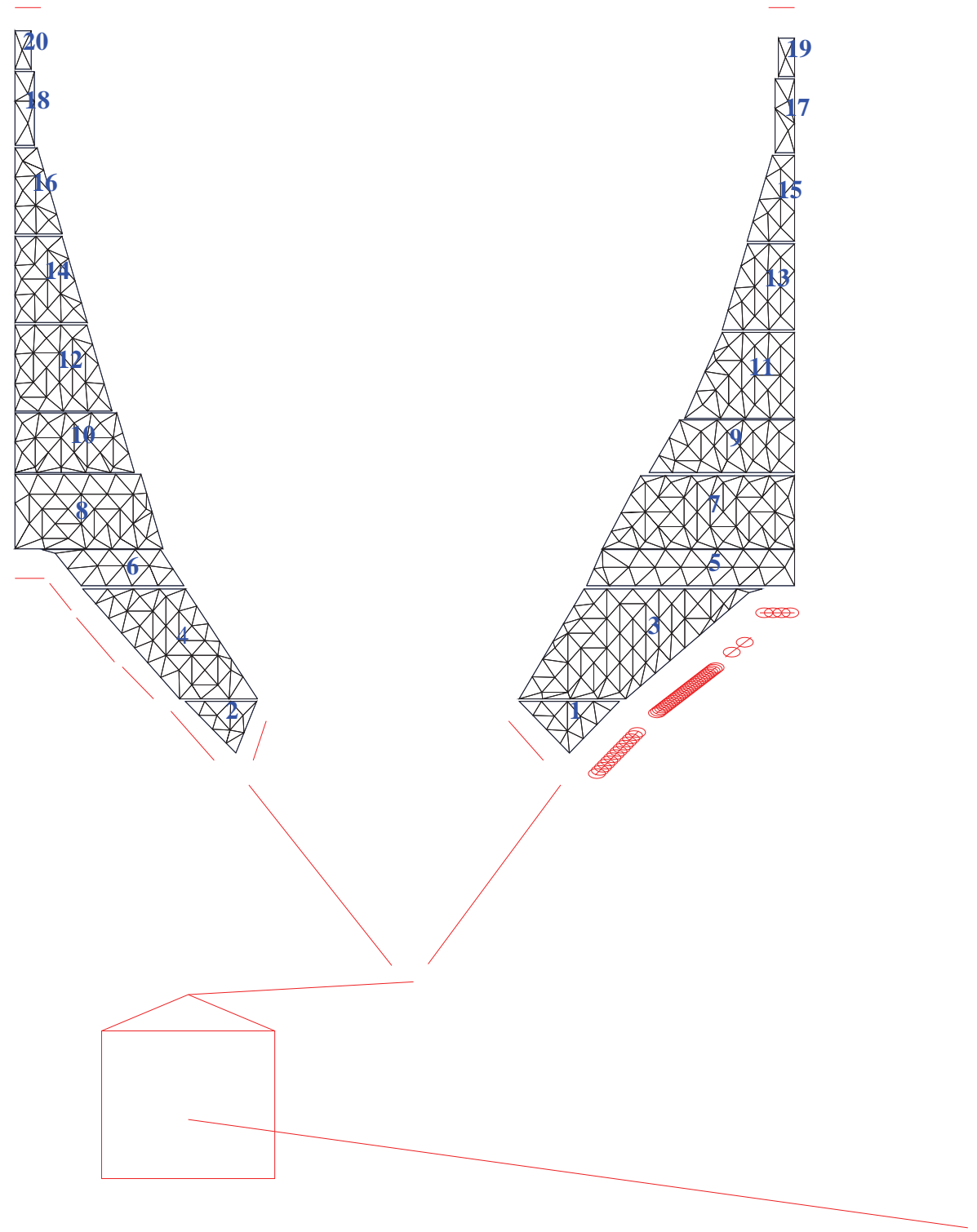

Fig. 3. Layout of reference trawl displaying FEM triangulation of the net with panel numbering scheme. Mesh discretization size is $2 \mathrm{~m}$. In the following fig. 4 we detail the partitioning of panel number 3 and in fig. 5 the connectivity between panels 1 and 3 and assembly with surrounding cables are displayed.
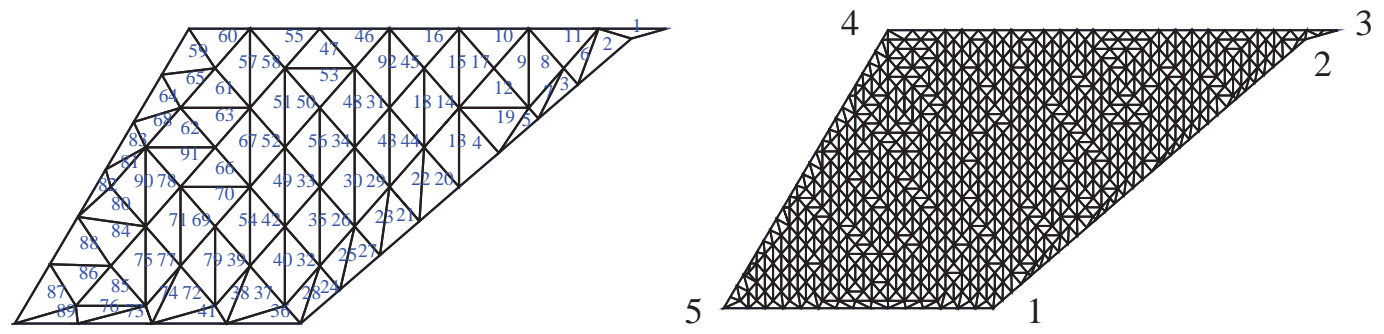

Fig. 4. Partitioning of panel number 3 into finite elements with numbering scheme. The mesh discretization size is $2 \mathrm{~m}$ on the left and $0.5 \mathrm{~m}$ on the right where nodes are displayed. 


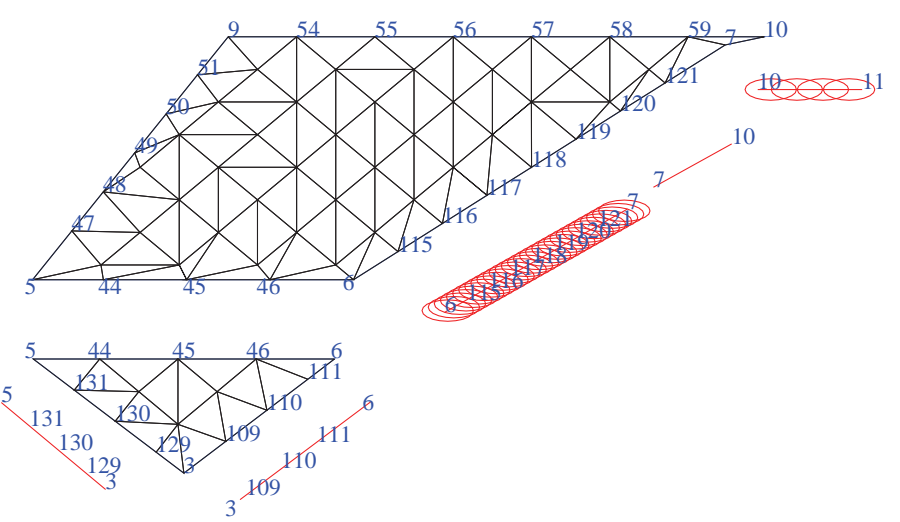

Fig. 5. Display of panels 1 and 3 showing finite element connectivity and assembly with surrounding cables.

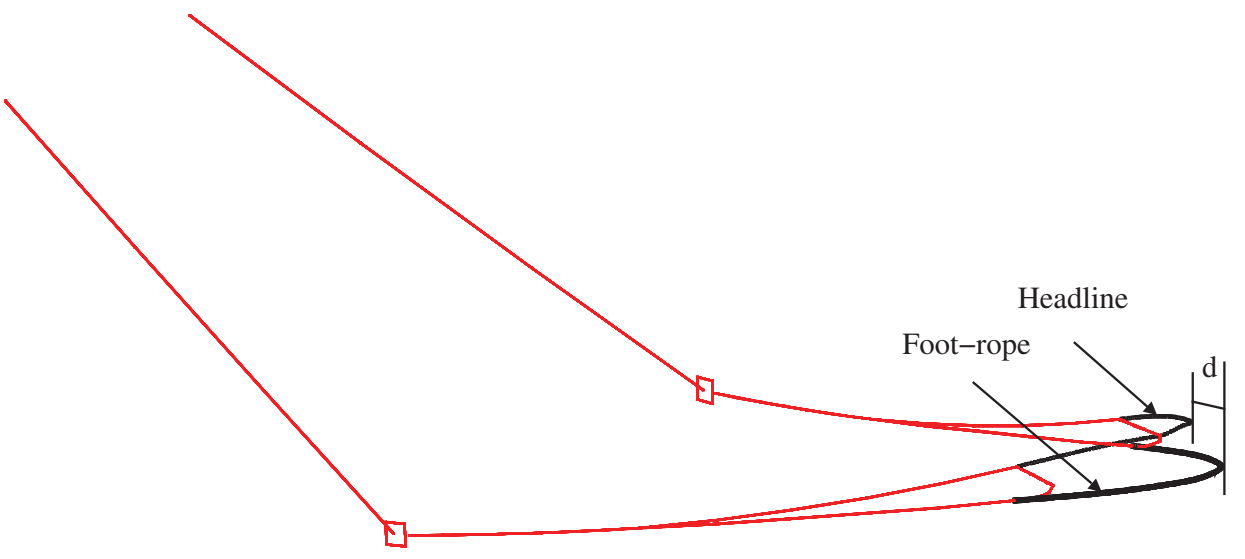

Fig. 6. Part of the trawl (The netting has been hidden). The warps are on the left, the doors are the squares. The foot-rope is behind the headline at a distance $\mathrm{d}$.

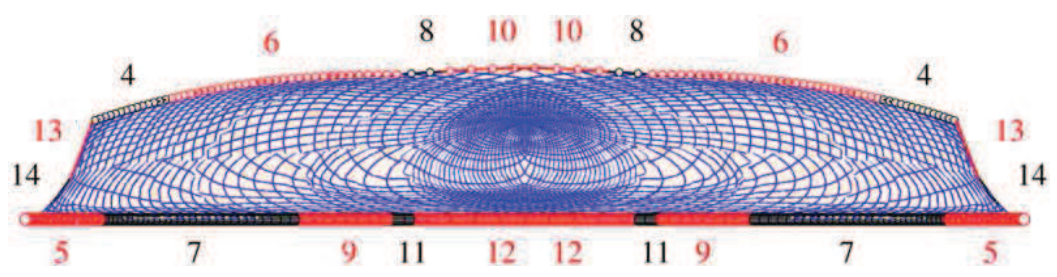

Fig. 7. Front view shape of reference trawl displaying cable number without ancillary rigging cables nor door structure (see fig. 1). The numbering scheme is symmetric with respect to a vertical mirror plane situated at the center of the trawl. Only 1 twine out of 10 is drawn. 

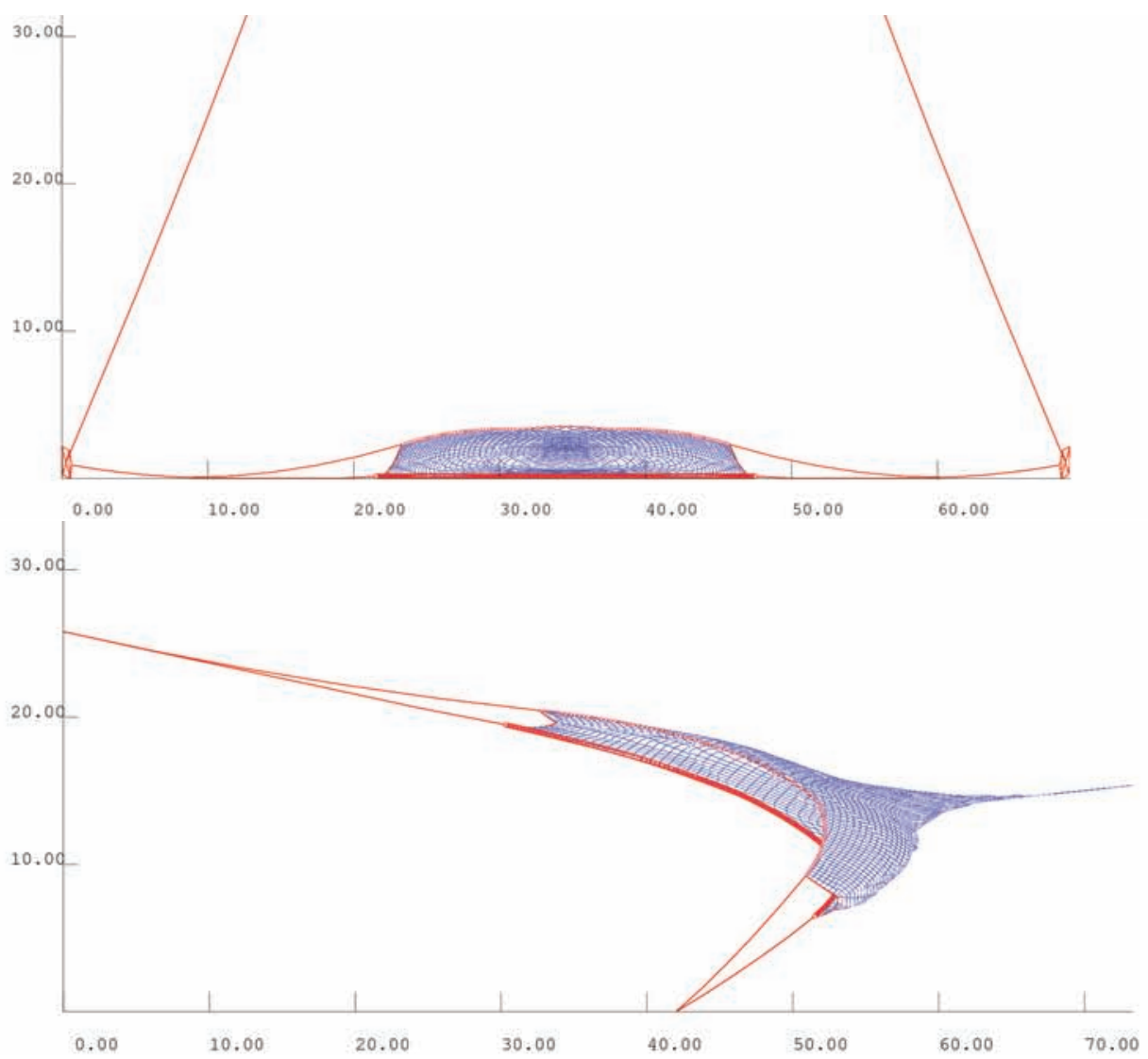

Fig. 8. Frontview (top) and 3D (bottom) aspects of the reference bottom trawl. We display a zoom on the netting and only 1 twine out of 10 are drawn. Since the top leg (cable \# 2 in fig. 1) supports the entire fishing net, we expect its length to play a major role as discussed in the text. 

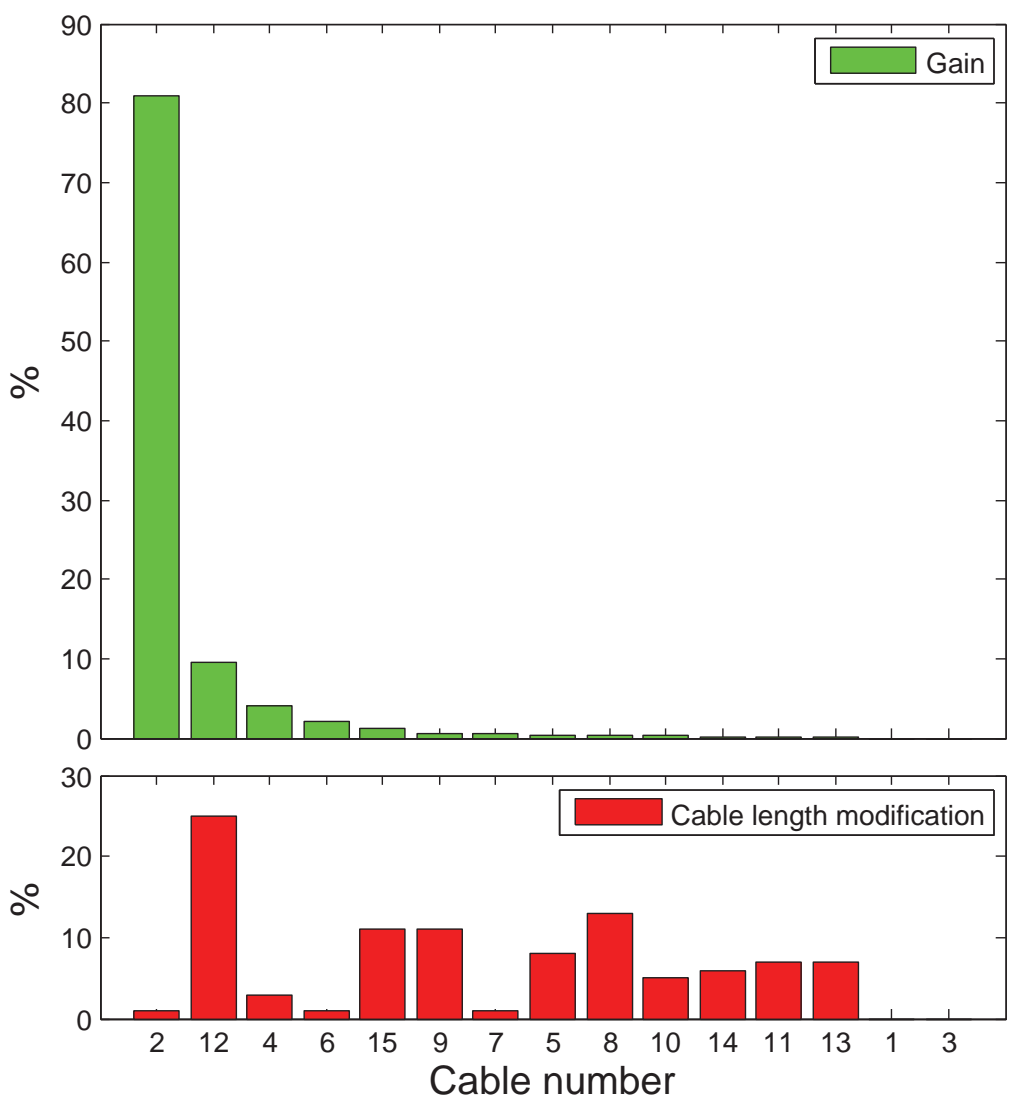

Fig. 9. Percentage length modification (lower panel) and individual percentage (upper panel) reduction attributed to each cable appearing by its contribution to total economy gain. Notice that cable \# 2 provides the largest part to total gain. 


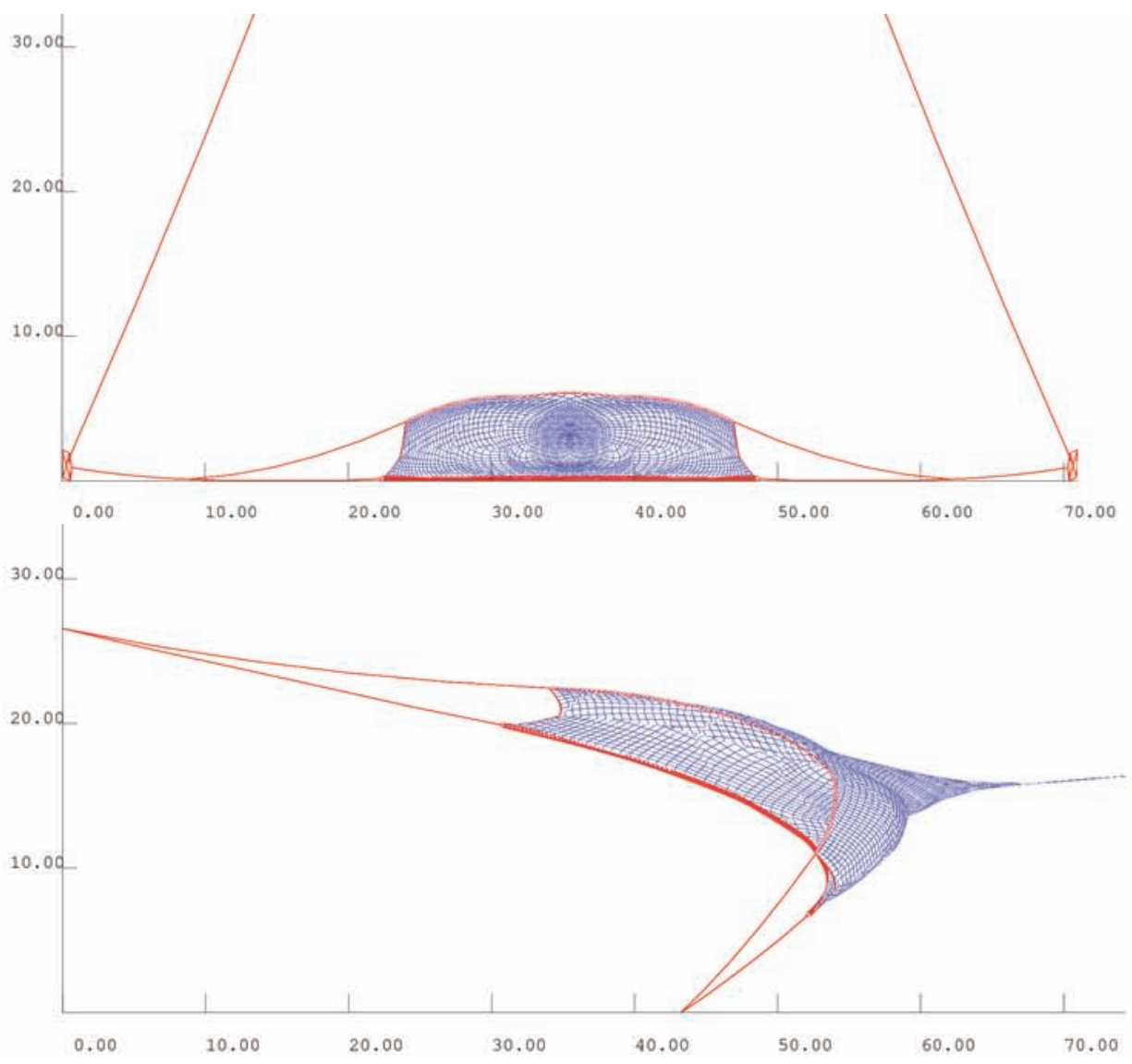

Fig. 10. Above: Frontview of the trawl rounded through changing the lengths of cables \# 2, 4 and 12 only in the reference trawl. Below: 3D aspect of the optimized trawl. 

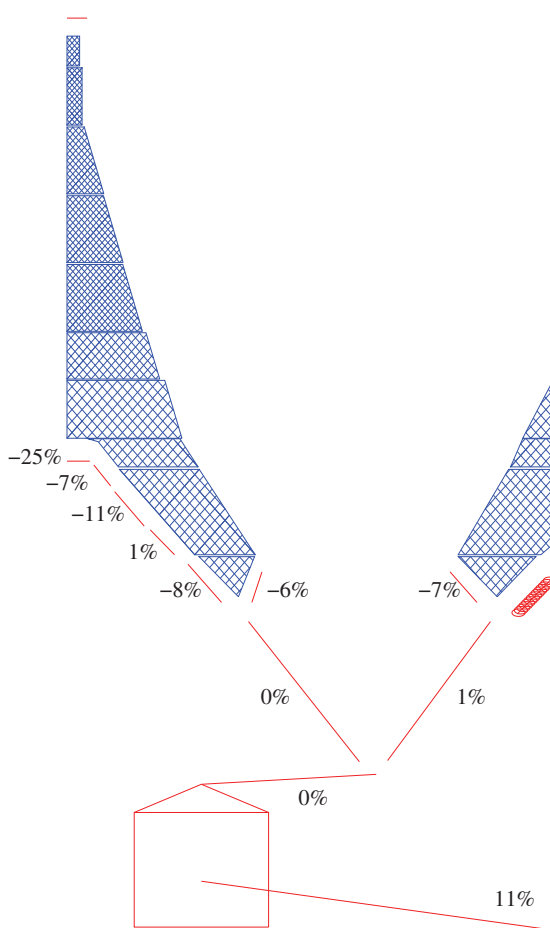
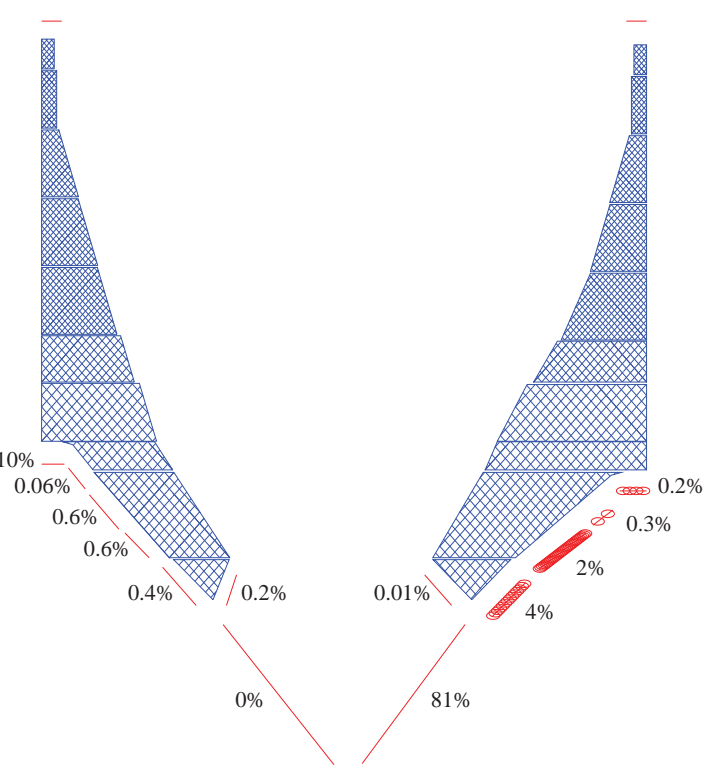

Fig. 11. Display of trawl showing cable length modification (left) and corresponding OF reduction in percent (right).

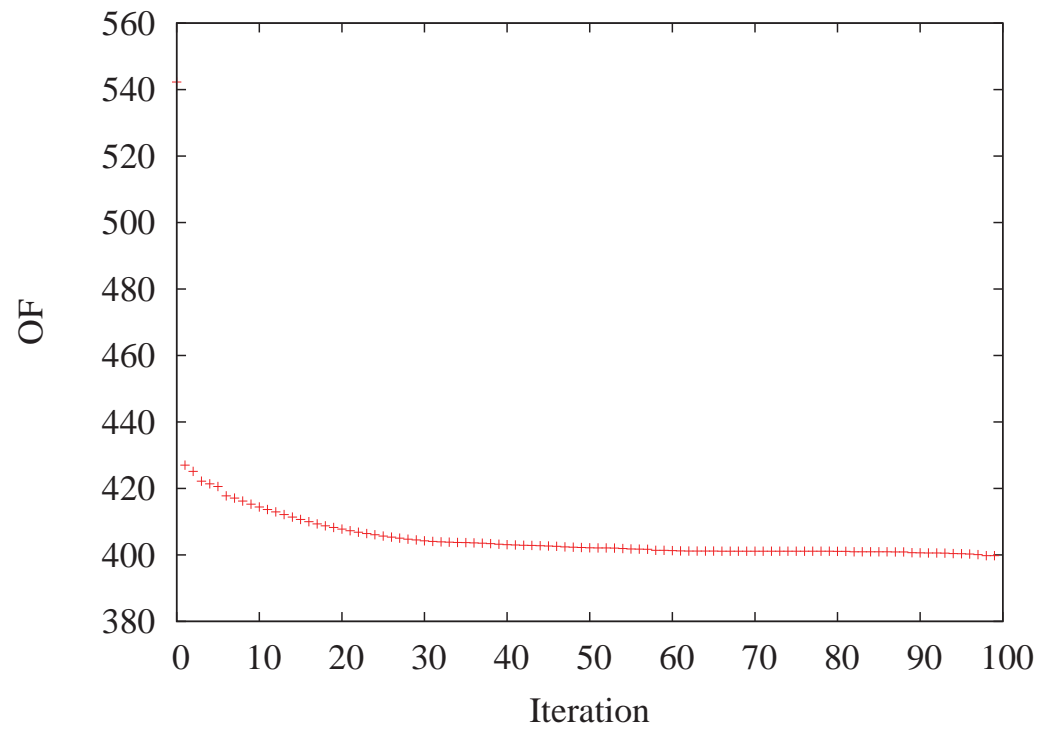

Fig. 12. Variation of the OF as a function of iteration number in the SOT case with a PR of $1 \%$. 


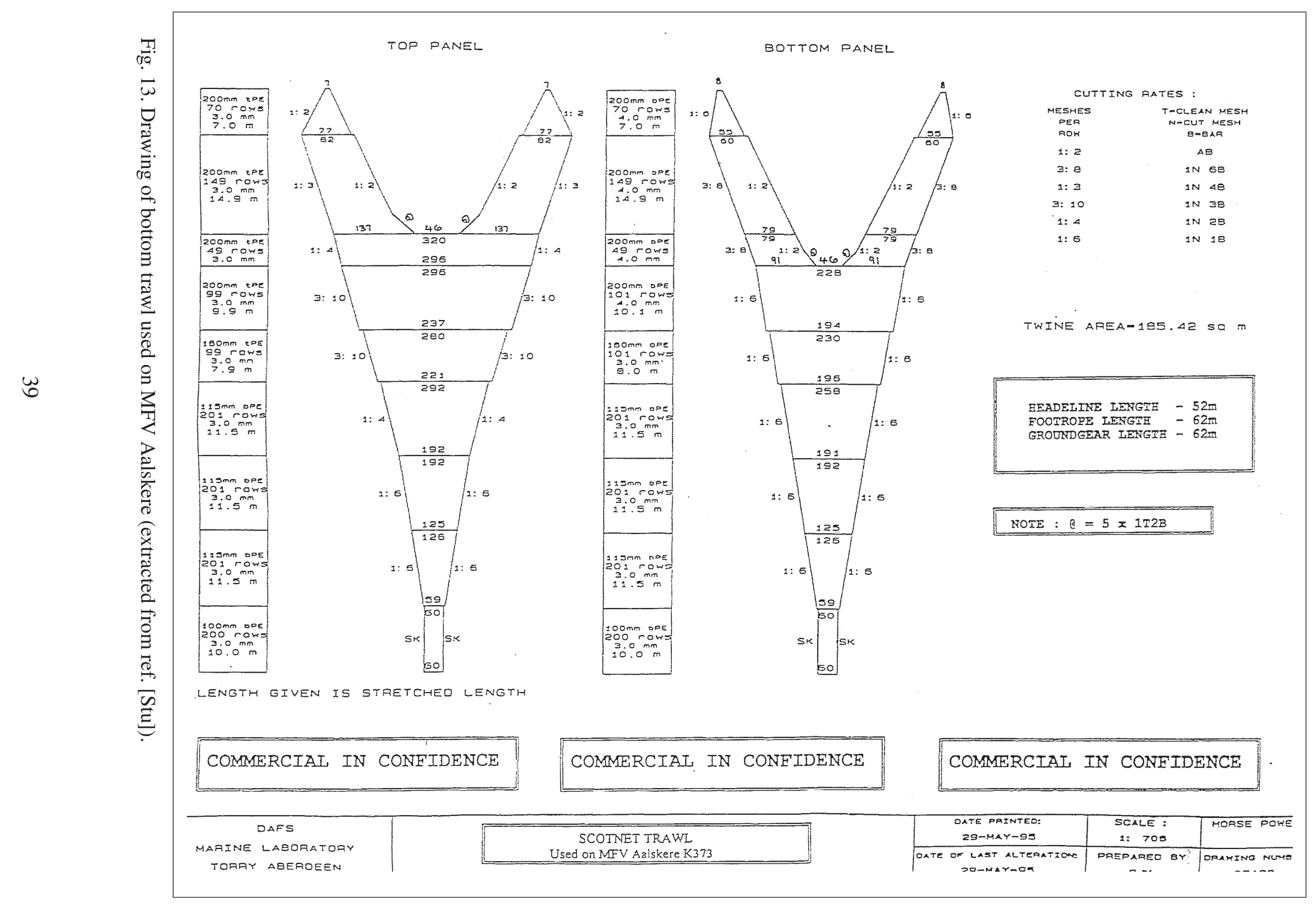




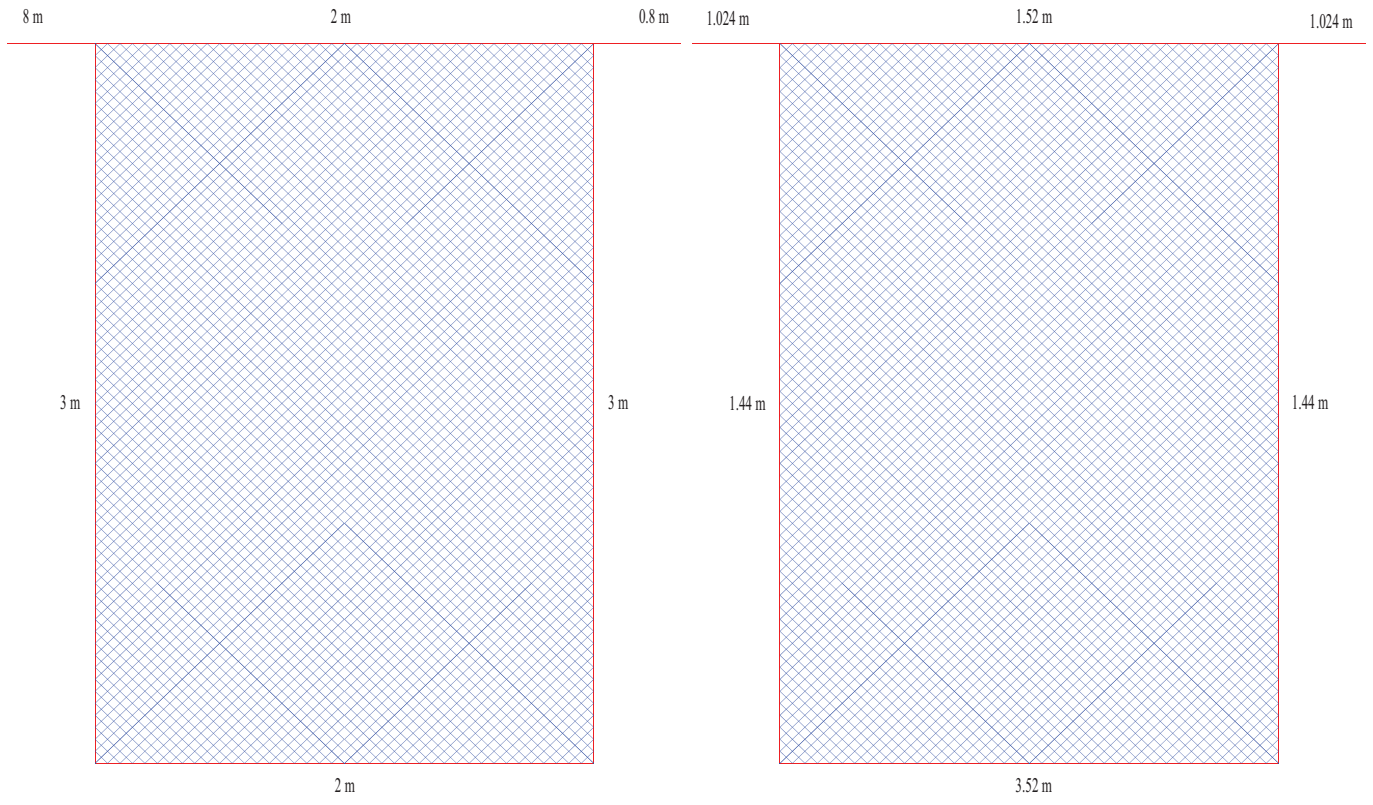

Fig. 14. Reference net (left) with dimensions $80 \times 120$ in mesh units and optimized result (right). Cable lengths are indicated. One mesh out of two is displayed.

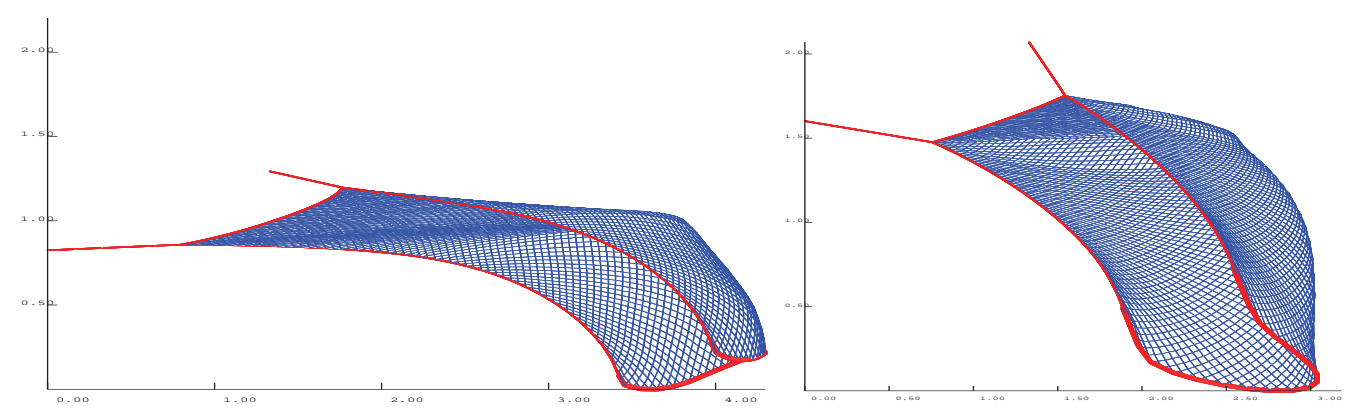

Fig. 15. 3D sideview of the reference net and the optimized case. 